\title{
Experiment and Application of Coalcrete on Roadway Stability: A Comparative Analysis
}

\author{
Guichen Li, ${ }^{1}$ Yuantian Sun $\mathbb{D}^{1},{ }^{1}$ Junfei Zhang $\mathbb{D}^{2},{ }^{2}$ Qianjin Zhang $\mathbb{D}^{3}{ }^{3}$ Changlun Sun, \\ Suhui Zhang, ${ }^{1}$ and Ruiyang $\mathrm{Bi}^{1}$ \\ ${ }^{1}$ Key Laboratory of Deep Coal Resource Mining, Ministry of Education of China, School of Mines, \\ China University of Mining and Technology, Xuzhou 221116, China \\ ${ }^{2}$ Department of Civil, Environmental and Mining Engineering, The University of Western Australia, Perth, WA 6009, Australia \\ ${ }^{3}$ State Key Laboratory of Hydraulics and Mountain River Engineering, Sichuan University, Chengdu 610065, China
}

Correspondence should be addressed to Yuantian Sun; yuantiansun@cumt.edu.cn, Junfei Zhang; junfeizhang2010@163.com, and Qianjin Zhang; 2019323060001@stu.scu.edu.cn

Received 23 August 2019; Revised 18 January 2020; Accepted 5 May 2020; Published 17 June 2020

Academic Editor: Hongtao Zhu

Copyright (c) 2020 Guichen Li et al. This is an open access article distributed under the Creative Commons Attribution License, which permits unrestricted use, distribution, and reproduction in any medium, provided the original work is properly cited.

Improving roadway stability in deep underground mines is quite challenging, as the conventional support structures easily fail. Roadway collapse and large deformation occur just several months after tunnel excavation. In this study, a relatively new prereinforcement technique, the jet grouting (JG), is introduced to improve roadway stability. A field test was performed for evaluating the practicability and applicability of JG in soft coal mass. A series of laboratory tests were conducted to assess the properties of coalcrete (coal-grout after JG treatment). A two-dimensional numerical model was established for validating the input parameters. Based on the verified model, three JG support cases for roadway were modeled and compared with a conventional support case, namely, the currently used support in this mine "rock bolts + U-shaped steel set + shotcrete." The results show that the proposed prereinforced JG support structures can considerably control the deformation and failure zone of the roadway and improve the bearing capacity of coal mass. The mechanism of maintaining roadway stability using JG techniques is further revealed. Some suggestions are further presented to improve the stability of the jet-grouted roadway.

\section{Introduction}

The stability of the roadway is tightly related to coal production and the safety of miners. To maintain roadway stability, some typical methods including rock bolts system [1-3] and U-shaped steel set [4] have been successfully applied in shallow coal mass. However, with the increase of mining depth, the aforementioned support methods may fail to keep roadway stable due to high geostress and tectonic stress and soft coal mass [5]. In these cases, large deformation of roadway, e.g., floor heave, roof subsidence, and sidewall convergences, appears commonly [6]. Many engineering practices have proved that using a single support method is extremely difficult or sometimes impossible to control the large deformation especially in the deep underground roadways with weak surrounding rock mass [7].
Consequently, compound support techniques such as "boltscables-shotcrete-square confined arch" [8] and "bolts-cables-U-shaped steel set-shotcrete" were designed and applied in poor geological conditions. These support schemes can reduce roadway deformation to some extent, while they cannot prevent the long-duration deformation of roadway effectively due to the rheological properties of soft rock mass under the high-stress state [9].

To deal with this problem, grouting, as an additional reinforcement method to main support systems, was utilized for considerably improving the mechanical properties (cohesion and friction angle), integrity, and stress state of the surrounding rock mass [10, 11]. Generally, the delayed grouting on the roadway was widely employed to improve the strength and deformation-resisting ability of soft and fractured surrounding coal mass, when other primary 
support structures have been installed [12]. Based on this grouting method, pregrouting before roadway excavation was proposed and applied in many underground projects such as reinforcement of headgates and tailgates [13], enhancement of heading face [14], and water inflow prevention [15]. In these projects, the pregrouting technique increased the overall quality of coal mass and, therefore, improved its self-bearing capacity. However, it should be noted that the currently used pregrouting approach is limited by the groutability of materials [16]. So, it could only be used as a supplement for the main support system. Also, it is noted that the coupling support system, e.g., "bolt-cable-U-shaped steel set-shotcrete-grouting" is too complex to operate conveniently. Constructing each part of the system is timeconsuming and strenuous, which would decrease tunneling speed and increase costs. Furthermore, according to the fundamental idea of the New Austrian Tunneling Method (NATM), the aim of support system for roadway is to improve the self-stabilization ability or load-bearing capacity of the soft coal seam. Thus, it is necessary to propose a support method to simplify the compound support system and draw on the advantages of pregrouting.

Jet grouting (JG) technique, a prereinforcement approach, is normally used for soil ground improvement [17]. Currently, the subhorizontal jet grouting has been used in tunnel construction including tunnel canopy [18], collapsed tunnel recovery [19], and jet-grouted umbrellas in a tunnel [20]. This method reinforces the surrounding loose soil or fragmented rock ahead of tunnel face with jet-grouted columns, which effectively controls the convergence and extrusion of the tunnel. Based on different geological environments, the product of JG is generally called soilcrete or sandcrete, i.e., a mix of cement grout with soil or sand, possessing some special advantages including low deformability and high strength. The mechanical properties of soilcrete or sandcrete played a crucial role in the stability of a jet-grouted tunnel, which has been studied by scholars [21-24]. Inspired by this, the coalcrete generated by JG technique for improving underground soft coal mass was reported recently [25]. The JG processes can be simply formulated as follows [26]. The high-pressure grout with a high-velocity jet is injected into soft coal mass through a small nozzle, and then, with the rotation of drill stem, the grout is mixed with coal particles to create coal-cement composite, i.e., coalcrete; a coalcrete column is then formed as the drill withdraws continually; then along the roadway profile, the next coalcrete column overlaps the former one with a certain length; finally, a JG coalcrete prereinforced support system is formed. Then, the shotcrete and U-shaped steel sets could be used for further strengthening the support $[27,28]$. The control effect of JG coalcrete columns on roadway stability should be analyzed systematically. In addition, due to the influence of JG pressure, coal mass strength, and grout materials, the diameter of coalcrete column varies. Therefore, the size effect on the mechanical properties of coalcrete should be considered in this study, though the traditional mechanical parameters of coalcrete such as strength and Young's modulus have been studied based on small samples in previous studies.
This study investigates the support effect of JG coalcrete on roadway stability and its mechanism. Based on the field observation of the JG test, the applicability of JG in soft coal mass was evaluated. Laboratory tests of coalcretes considering size effects were conducted to determine mechanical parameters. A 2D numerical model was established to verify the input parameters by comparing the modeling results with filed measurements. Furthermore, by the verified numerical method, three typical JG support cases and one conventional support case were compared and analyzed deeply in terms of roadway deformation, failure zone, and stress state. Based on the results, some suggestions were further listed. This pioneering work proposes a workflow for designing JG parameters in practice and facilitates the application of JG presupport system in the roadway with soft coal mass.

\section{Field and Laboratory Tests}

2.1. Field JG Test. A field trial of JG was conducted in Guobei coal mine. The thickness of the coal seam in this mine is about $10 \mathrm{~m}$ and the roadway was normally driven along the floor. Due to the low-strength coal mass, the collapse and spalling in the driving face normally appeared (Figures 1(a) and 1(b)). Moreover, with the conventional compound support system (U-shaped steel set + rock bolts + shotcrete), large roadway deformation still occurred just 1 month after tunneling work started.

Considering these cases, the jet grouting technique was first tried in soft coal mass to improve its self-stabilization ability and form a reinforced support system for the roadway. The schematic diagram of JG treatment for coal mass is shown in Figure 2. In the field, when the drill stem withdrew from the hole in coal mass, the high-pressure cement grout $(20 \sim 26 \mathrm{MPa})$ rotated with the rod and therefore cut coal mass continuously. The fragment coal particles mixed with cement grout and then a coalcrete column was formed. Specifically, the rotating speed and the reverse speed of the rod were $18 \mathrm{r} / \mathrm{min}$ and $20 \mathrm{~cm} / \mathrm{min}$, respectively. When the processes of jet grouting finished, the mechanical properties of loose raw coal were entirely changed. The strength and deformation-resisting ability of the coal were improved. The diameter of formed coalcrete in the field is normally around $400 \mathrm{~mm} \sim 600 \mathrm{~mm}$. According to the engineering practice of controlling a roadway in soft coal mass, the largest deformation normally occurs at the surface of the roadway because the broken coal mass surrounding the roadway is basically in the extent of $400 \mathrm{~mm}$ based on the borehole observation. Also, practice experience has proven that controlling the fractured coal mass around roadway profile is critical for maintaining long-term roadway stability. As described above, the prereinforced JG coalcrete column (diameter from $400 \mathrm{~mm}$ to $600 \mathrm{~mm}$ ) has higher strength and rigidity than raw coal mass, which means that the fractured coal in the corresponding range from the surface is replaced and controlled by coalcrete before roadway excavation. This meets the requirements of a roadway support system by such coalcrete columns and 


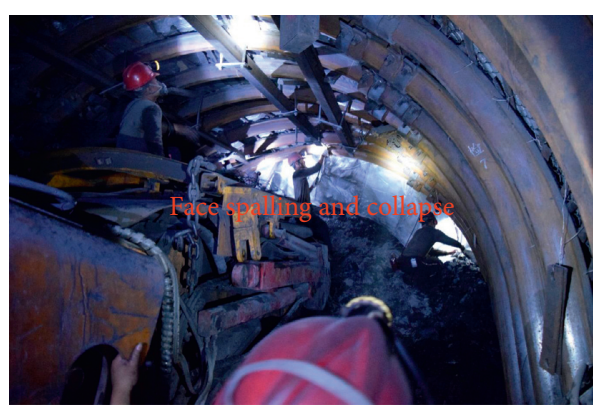

(a)

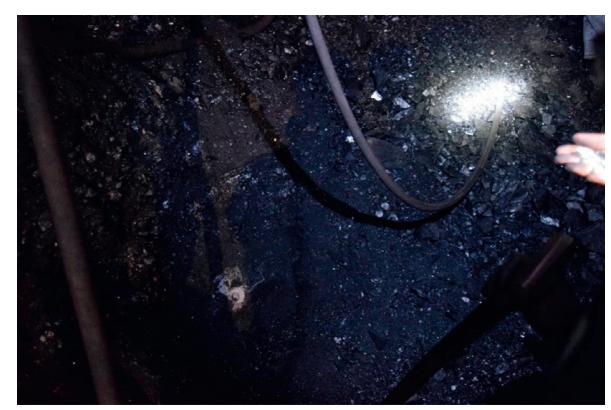

(b)

Figure 1: Field photos during the driving of roadway in soft coal mass. (a) Spalling and collapse at tunneling face. (b) The falling coal particles.

indicates that the jet grouting technique in soft coal mass is practicable and promising.

\subsection{Laboratory Tests of the Mechanical Properties of} Coalcrete. In practice, the coalcrete columns can improve the shear strength of soft coal mass before excavation and resist the surrounding stress after tunneling by constructing a stable arch structure [25]. Hence, it is necessary to evaluate the strength behaviors of coalcrete. A series of shear tests and uniaxial compressive tests considering the size effect were performed to assess the mechanical properties of coalcrete. To select reasonable mechanical parameters for the following numerical simulation, coalcrete specimens with different sizes were set as $50 \mathrm{~mm}, 100 \mathrm{~mm}, 150 \mathrm{~mm}$, and $200 \mathrm{~mm}$ cube. A direct shear test machine (YZW500, Jinan, China) was used for obtaining the shear parameters of coalcrete according to the designed shear tests scheme (given in Table 1). As for the uniaxial tests of the specimens, a displacement control with the loading rate $0.5 \mathrm{~mm} / \mathrm{min}$ was applied by a compression testing machine (MTS C64, Minnesota, USA).

2.3. Coal Measure Rock Mass Properties. The surrounding rock mass in the roadway is in complex geological conditions such as groundwater conditions, fractures, and discontinuities. In this paper, the geological strength index (GSI) was applied to obtain the parameters of rock mass [29]. Furthermore, the rock mass rating (RMR) classification system was applied to determine the GSI; as RMR is calculated from a series of ratings of various parameters including UCS of rock, RQD, and joint spacing, it is more quantitative and practicable [30]. The empirical correlation between GSI and RMR is given in equation (1) [31]. Based on the RMR values obtained from the field observations, the GSI values of various rock masses are summarised in Table 2. Moreover, the intact rock properties such as compressive strength $\left(\sigma_{c i}\right), m_{i}$ constant, were tested in the laboratory. Then, the rock mass properties (strength and deformation modulus, shown in Table 2) were calculated based on the equations in the literature $[32,33]$ :

$$
\mathrm{GSI}=\mathrm{RMR}-5 .
$$

The Hoek-Brown criterion is given as follows:

$$
\sigma_{1}=\sigma_{3}+\sigma_{c i}\left(m_{b} \frac{\sigma_{3}}{\sigma_{c i}}+s\right)^{a} .
$$

In equation (2), $m_{\mathrm{b}}, s$, and $a$ are the rock mass constants. In order to calculate the rock mass deformation modulus, GSI-based empirical equation is given as

$$
E_{\text {mass }}=E_{i}\left(0.02+\frac{1-(D / 2)}{1+e^{((60+15 D-G S I) / 11)}}\right),
$$

where $E_{\mathrm{i}}$ means the deformation modulus of intact rock.

\section{Numerical Analysis Method}

3.1. Modeling Framework and Procedure. The numerical method has been successfully applied in many cases to analyze the roadway stability nowadays. The primary objective of this work is to analyze the control effect of JG columns on roadway stability by comparing the conventional support schemes with the JG support system. Although the displacement and stress fields during tunneling should be analyzed using three-dimensional numerical methods, two-dimensional methods were used successfully to analyze the relevant problems such as surface settlements and tunnel convergence [34], the effect of construction procedures [35], etc. Besides, compared with the three-dimensional model, the $2 \mathrm{D}$ model was more efficient and less time-consuming, which has been widely used for analyzing the effect of JG application in tunnels as well $[18,36]$. In this study, the software RS2 was introduced to reveal the effect of JG coalcrete on a representative roadway cross section.

Same as the size in the field, the width and height of the roadway in the numerical model are $5.6 \mathrm{~m}$ (symbolized $D$ ) and $4.8 \mathrm{~m}$, respectively (shown in Figure 3 ). To reduce the influence of mesh size and boundary conditions, a series of trial analyses were performed. Finally, the model domain is $5 D \times 5 D$ and the appropriate mesh discretization is 3-noded triangular elements. The geometry of the model is shown in Figure 3(a) and the enlarged rectangular region represents different support systems, i.e., conventional support system (rock bolts + U-shaped shed + shotcrete) (Figure 3(b)) and 


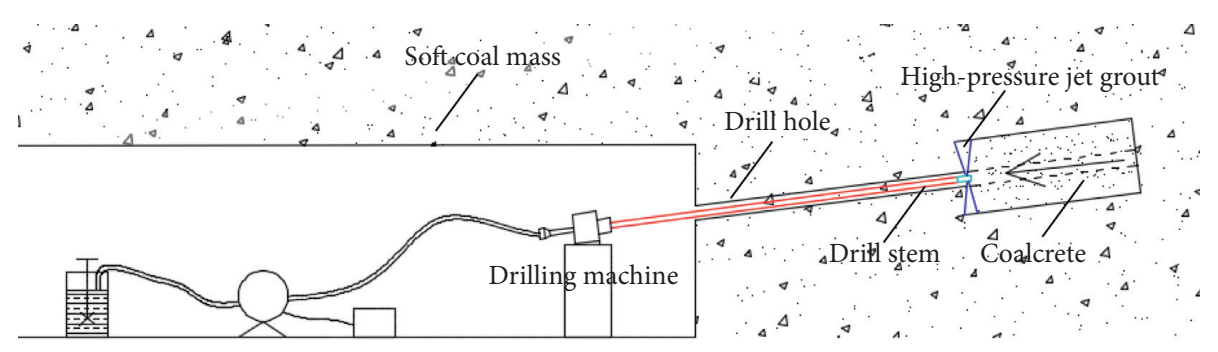

Figure 2: Schematic diagram of JG treatment.

Table 1: Design of shear tests.

\begin{tabular}{lccc}
\hline Specimen size $(\mathrm{mm})$ & Normal stress $(\mathrm{MPa})$ & Number of specimens in each group & Shear velocity $(\mathrm{mm} / \mathrm{min})$ \\
\hline $50,100,150,200$ & $2,3,5,7$ & 4 & 0.5 \\
\hline
\end{tabular}

TABLE 2: Coal measure rock mass properties.

\begin{tabular}{lcccccccccc}
\hline \multirow{2}{*}{$\begin{array}{l}\text { Lithology unit } \\
\end{array}$} & \multicolumn{3}{c}{ Rock properties by indoor test } & \multicolumn{4}{c}{ Field } & \multicolumn{3}{c}{ Rock mass properties by formula conversion } \\
& $m_{\mathrm{i}}$ & $\sigma_{c i}(\mathrm{MPa})$ & Poisson's ratio $(v)$ & $E_{i}(\mathrm{GPa})$ & $\mathrm{RMR}$ & $\mathrm{GSI}$ & $c(\mathrm{MPa})$ & $\phi\left({ }^{\circ}\right)$ & $\sigma_{t}(\mathrm{MPa})$ & $E_{\mathrm{mass}}(\mathrm{GPa})$ \\
\hline Sandstone & 9 & 85.8 & 0.22 & 18.6 & 72 & 67 & 3.45 & 42 & 0.79 & 12.5 \\
Mudstone & 9 & 38.5 & 0.29 & 3.61 & 40 & 35 & 1.24 & 27 & 0.03 & 0.4 \\
Coal & 30 & 7.0 & 0.39 & 5.0 & 35 & 30 & 0.98 & 24 & 0.15 & 0.50 \\
\hline
\end{tabular}

JG prereinforced support system (coalcrete + shotcrete) (Figure 3(c)). The established model was fixed in the horizontal direction at the right and the left side. The bottom parts of the boundary were pinned. These models contained approximately 22,000 elements with the optimum mesh size after testing. Due to the effect of last working face retreat on the stresses at the position of the studied roadway, the principal stresses would deflect. Therefore, based on the previous study of 3D global-2D local modeling method [37], the stresses for the 2D model were transformed from the three-dimensional stresses. The applied vertical stress and horizontal stress are 19.23 $\mathrm{MPa}$ and 11.21 MPa, respectively.

Selecting a proper constitutive model for materials is essential. In this study, the Mohr-Coulomb (MC) model was utilized for modeling the rock mass and the coalcretes, which has been commonly used in coal measures rocks and jet-grouted materials (soilcrete, sandcrete, etc.) reported in the literature [38, 39]. Furthermore, the mechanical behavior of coalcrete is studied in Section 4.1, in which the results show that coalcretes' failure suited the Mohr-Coulomb criterion well. A linear elastic constitutive model is used for modeling shotcrete and U-shaped shed by structural elements according to recommendations [40, 41]. Several key steps were performed for establishing various models as follows:

(1) The boundaries were set based on Figure 3(a), and stresses were initialized according to calculation.

(2) The mechanical parameters were allocated to rock mass (Table 2) and coalcretes (Table 5 in Section 4.1). It should be noted that the coalcrete columns surrounding the roadway profile were installed subhorizontally before tunnel face excavation.
(3) The arched roadway section was excavated and supported simultaneously. In this stage, models were divided into two types (see Figures 3(b) and 3(c)). The conventional support system, i.e., the rock bolts, U-shaped shed, and shotcrete, was installed at this stage. The support materials are consistent with the field and their properties are summarised in Table 3. By comparison, the proposed JG support system just needs to spray shotcrete since the prereinforced coalcrete columns have been already generated in stage 2 .

(4) Different model simulations were run for various purposes. One model is used for corroborating input parameters (conventional support, verification in Section 3.2). Other models are employed for investigating the effect of the JG support system on roadway stability (comparison in Section 4.3).

3.2. Verification of the Established Model. The 2D numerical analysis should consider the three-dimensional face effect after tunneling, as the stress redistribution and deformation occur during tunnel excavation. There are some techniques used in the 2D plane strain model, such as stress relief method [42], stiffness reduction method [43], and disk calculation method. Among these approaches, the stress relief method, also called convergence-confinement method, was commonly utilized for modeling around tunnel face [34]. Referring to this method, a displacement release method was presented [44]. In this study, the displacement release ratio was calculated based on the previous recommendation [45]. 


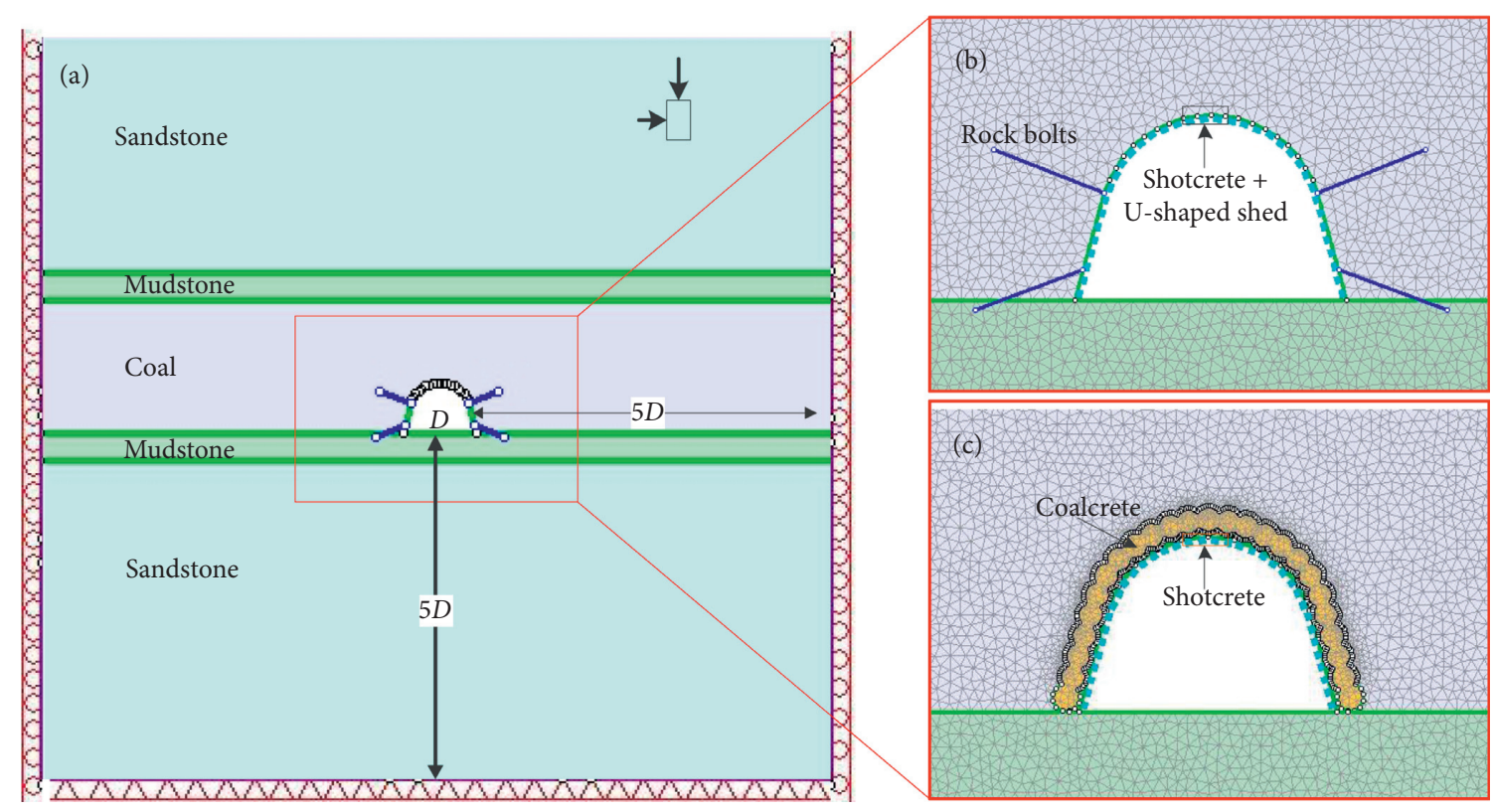

Figure 3: The established 2D numerical models for roadway. (a) The geometry and coal measures stratum of the model. (b) Enlarged view of traditional support. (c) Enlarged view of JG support system.

TABle 3: Properties of support materials.

\begin{tabular}{lccc}
\hline Parameters, unit & Rock bolt & U-shaped shed & Shotcrete \\
\hline Elastic modulus, GPa & 200 & 200 & 30 \\
Poisson's ratio & 0.3 & 0.25 & 0.15 \\
Diameter/thickness, mm & 22 & 15 & 100 \\
Unit weight, kN/m ${ }^{3}$ & - & - & 24 \\
Length, mm & 2400 & - & - \\
Pretensioning, kN & 80 & - & - \\
\hline
\end{tabular}

The displacement release ratio for models increased from $0 \%$ to $100 \%$, and each model has run for enough steps to reach the balance. When the ratio was set as $100 \%$, the model could be regarded as that the tunnel face was far away from the studied cross section [46]. The displacement release ratio is related to real time, which means the stress acting on roadway can be expressed as the function of time, as the in situ displacement and its corresponding time were recorded simultaneously. By this method, the real stresses on roadway increase over time, and therefore the roadway deformation exhibits rheology property, which has been confirmed in deep tunnel in the literature [47]. In practice, convergence-measuring pins were adopted to measure the sidewall convergence with time (shown in Figure 4). Then, the displacement/stress release rate was calculated, and eight representative results were further selected (as shown in Table 4).

Correspondingly, a 2D numerical model was constructed according to the modeling procedures described above. In the model, there are eight stages of applied stresses, which can simulate the roadway deformation over time. Figure 5 shows the evolution of sidewall convergence with time. Furthermore, the monitored deformation by the model was compared with the monitoring results in the field (Figure 4). As can be seen, the trend and magnitude of these

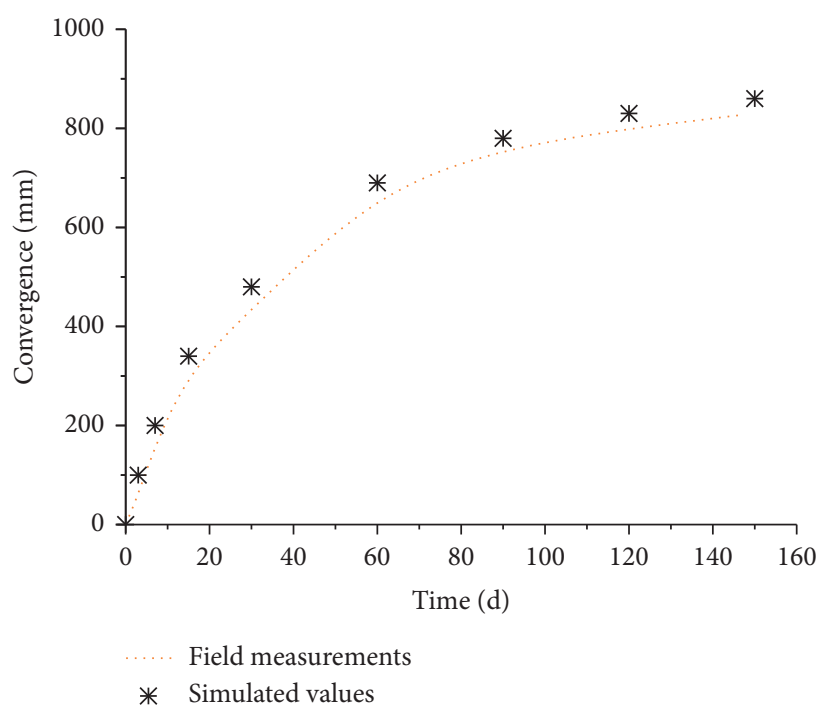

FIgURE 4: The comparison between measured convergences and calculated convergences in the representative roadway cross section.

values are very similar, confirming that the model is reasonable and accurate.

\section{Results and Discussion}

4.1. Mechanical Test Results of Coalcrete. The shear test results of coalcretes of various sizes under different normal stresses are shown in Figure 6. It can be seen that the shear stress increased linearly with the increase of normal stresses. Thus, the Mohr-Coulomb failure criterion is used for fitting the data obtained from the tests, as given in the following equation: 
TABLE 4: The calculated displacement release rate with time.

\begin{tabular}{lcccccccc}
\hline Time (days) & 3 & 7 & 15 & 30 & 60 & 90 & 120 & 150 \\
\hline Displacement/stress release ratio (\%) & 11.63 & 19.27 & 37.34 & 52.41 & 81.32 & 91.56 & 96.38 & 100 \\
\hline
\end{tabular}

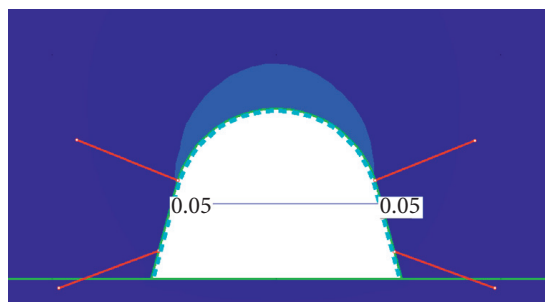

Displacement (m) $\begin{array}{lllllllllll}0.47 & 0.43 & 0.38 & 0.33 & 0.28 & 0.24 & 0.19 & 0.14 & 0.10 & 0.05 & 0.00\end{array}$

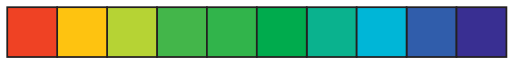

(a)

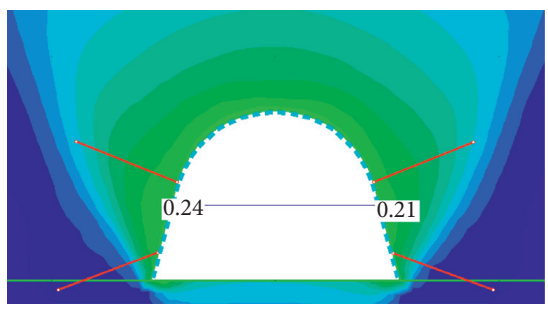

Displacement $(\mathrm{m})$

$\begin{array}{lllllllllll}0.47 & 0.43 & 0.38 & 0.33 & 0.28 & 0.24 & 0.19 & 0.14 & 0.10 & 0.05 & 0.00\end{array}$

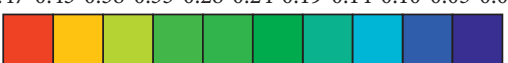

(d)

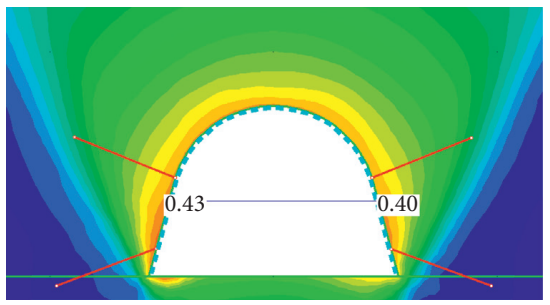

Displacement $(\mathrm{m})$

$\begin{array}{lllllllllllllll}0.47 & 0.43 & 0.38 & 0.33 & 0.28 & 0.24 & 0.19 & 0.14 & 0.10 & 0.05 & 0.00\end{array}$

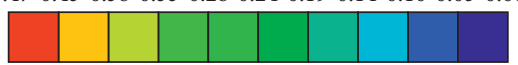

(g)

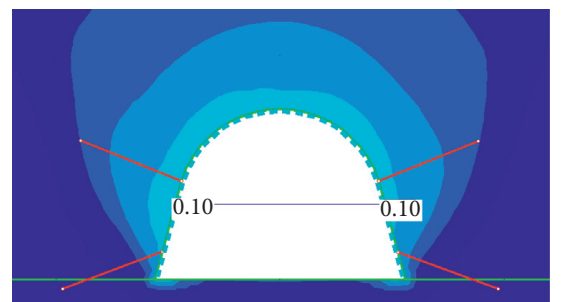

Displacement $(\mathrm{m})$

$\begin{array}{llllllllllllll}0.47 & 0.43 & 0.38 & 0.33 & 0.28 & 0.24 & 0.19 & 0.14 & 0.10 & 0.05 & 0.00\end{array}$

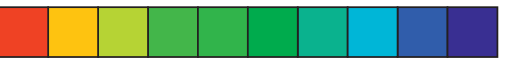

(b)

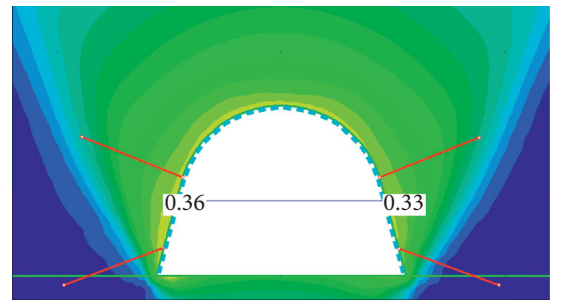

Displacement $(\mathrm{m})$

$\begin{array}{llllllllllll}0.47 & 0.43 & 0.38 & 0.33 & 0.28 & 0.24 & 0.19 & 0.14 & 0.10 & 0.05 & 0.00\end{array}$

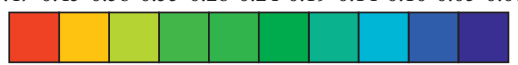

(e)

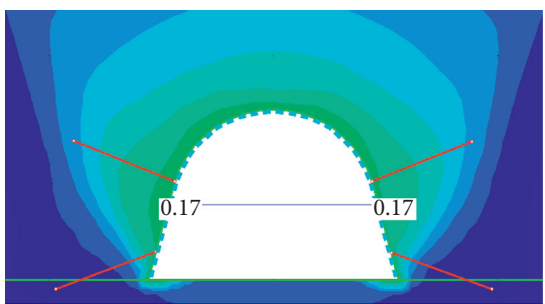

Displacement (m)

$\begin{array}{lllllllllll}0.47 & 0.43 & 0.38 & 0.33 & 0.28 & 0.24 & 0.19 & 0.14 & 0.10 & 0.05 & 0.00\end{array}$

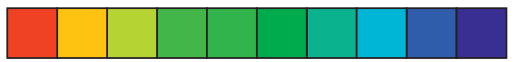

(c)

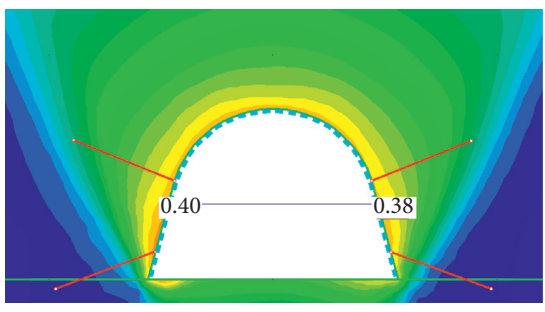

Displacement (m)

$\begin{array}{lllllllllllllllllll}0.47 & 0.43 & 0.38 & 0.33 & 0.28 & 0.24 & 0.19 & 0.14 & 0.10 & 0.05 & 0.00\end{array}$

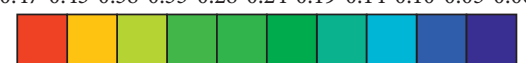

(f)

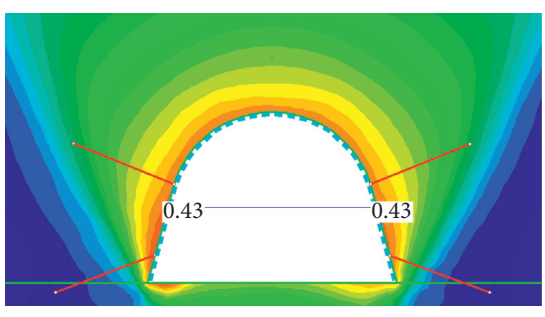

Displacement ( $\mathrm{m}$ )

$\begin{array}{llllllllllllllll}0.47 & 0.43 & 0.38 & 0.33 & 0.28 & 0.24 & 0.19 & 0.14 & 0.10 & 0.05 & 0.00\end{array}$

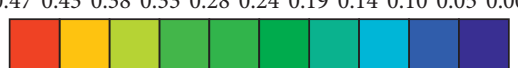

(h)

Figure 5: The calculated sidewall convergences from the 2D model with different stress release ratio. (a) $11.63 \%$, (b) $19.27 \%$, (c) $37.34 \%$, (d) $52.41 \%$, (e) $81.32 \%$, (f) $91.56 \%$, (g) $96.38 \%$, and (h) $100 \%$.

$$
\tau=\sigma \tan (\varphi)+c
$$

where $\tau, \varphi, c$, and $\sigma$ are the peak shear stress, friction angle, cohesion, and normal stress component, respectively.

It is clear that all coefficients exceeded 0.97 , which means that there was a strong correlation between shear stress and normal stress of coalcrete specimens under different sizes, and the failure of coalcrete obeyed the Mohr-Coulomb criterion well. The calculated cohesion and friction angle are presented in Table 5. Moreover, deformation modulus and uniaxial compressive strength (UCS) based on test results are also given in Table 5 . It can be due to the fact that the mechanical parameters of coalcrete such as cohesion, friction angle, deformation modulus, and UCS exhibit size effect, which are consistent with the experience and literature. In accordance with the recommendation in the studies [48], regression analysis with the fitting functions (shown in Table 5) was conducted. More specifically, the values of fitting coefficients $R^{2}$ were larger than 0.9 , demonstrating that the function had a good agreement with experimental results.

In practice, the diameter of coalcrete columns depended on jet-grouting pressure, coal mass conditions, rod withdraw speed, etc. In general, it varied from $400 \mathrm{~mm}$ to $600 \mathrm{~mm}$ in soft coal mass. Therefore, in this study, the typical diameter of the coalcrete columns, 300, 500, and $700 \mathrm{~mm}$, was selected for further analysis. According to the regression equations and Table 5, it is reasonable to determine the 


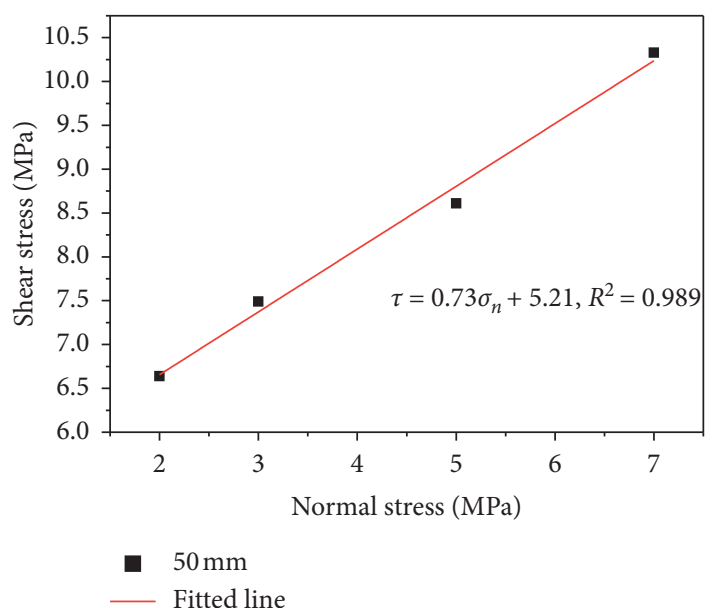

(a)

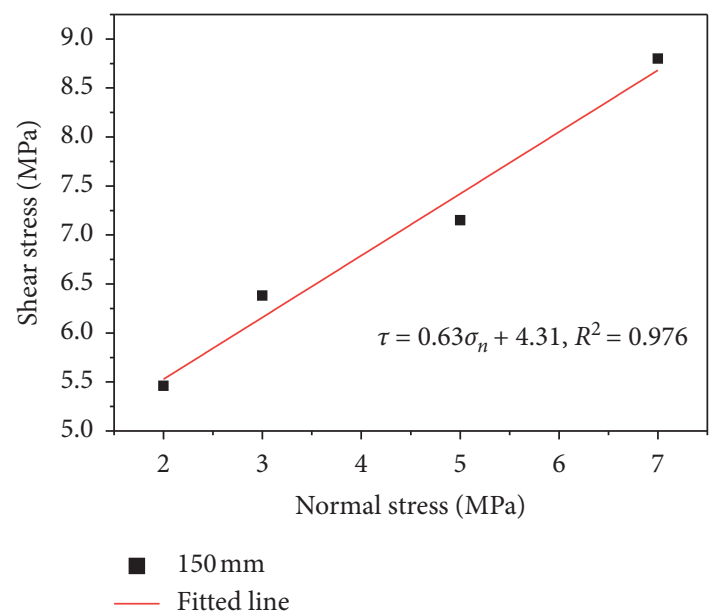

(c)

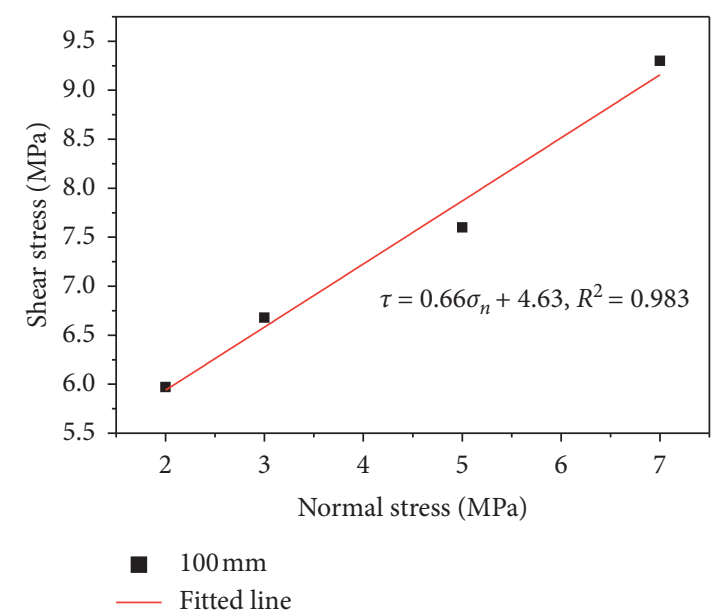

(b)

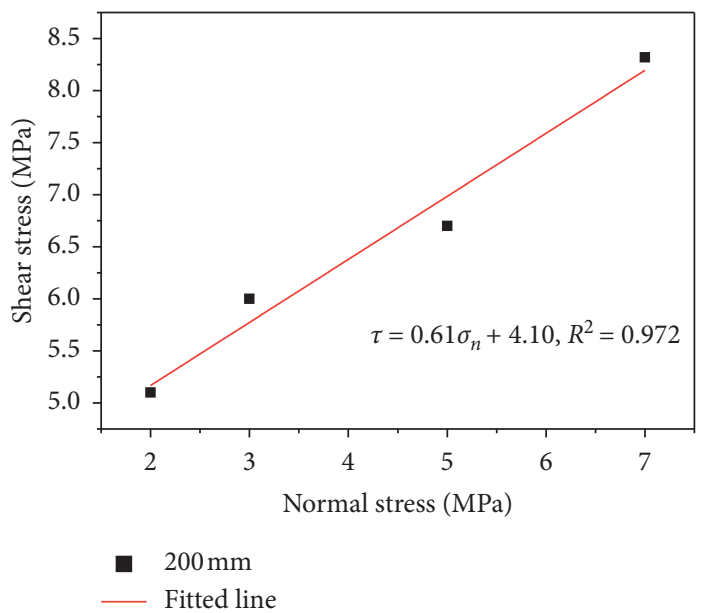

(d)

Figure 6: Shear tests results of coalcretes with different sizes. (a) $50 \mathrm{~mm}$, (b) $100 \mathrm{~mm}$, (c) $150 \mathrm{~mm}$, and (d) $200 \mathrm{~mm}$.

TABLe 5: The experimental and calculated mechanical parameters of coalcrete.

\begin{tabular}{|c|c|c|c|c|c|c|c|c|}
\hline \multirow{2}{*}{ Parameters } & \multicolumn{4}{|c|}{ Specimen size $(\mathrm{mm})$} & \multirow{2}{*}{ Fitting function } & \multicolumn{3}{|c|}{ Coalcrete size $(\mathrm{mm})$} \\
\hline & 50 & 100 & 150 & 200 & & 300 & 500 & 700 \\
\hline Cohesion (MPa) & 5.2 & 4.6 & 4.3 & 4.1 & \multirow{2}{*}{$y=a+b x^{c}$} & 3.87 & 3.59 & 3.42 \\
\hline Friction angle $\left({ }^{\circ}\right)$ & 36.1 & 33.4 & 32.3 & 31.4 & & 30.7 & 29.8 & 29.2 \\
\hline Deformation modulus (GPa) & 10.7 & 7.9 & 6.8 & 6.2 & \multirow{2}{*}{$y=b x^{c}$} & 5.14 & 4.16 & 3.62 \\
\hline UCS $(\mathrm{MPa})$ & 14.1 & 11.9 & 10.9 & 10.4 & & 9.45 & 8.45 & 7.86 \\
\hline
\end{tabular}

mechanical parameters of larger coalcrete. In this study, the tensile strength of coalcrete was regarded as 0.3 times that of UCS [49], which is different from the one-tenth of the compressive strength of rock materials [50]. The value of Poisson's ratio was set as 0.24 based on the test results. Normally, the values of Poisson's ratio with different sizes are similar regardless of the size.

4.2. Failure Mechanism of the Soft Coal Roadway. The mechanism of deformation and failure of roadway in conventional support scheme was analyzed by displacement monitoring results and the evolution of the failure zone of surrounding coal measure rock mass. The results are depicted in Figure 7. As can be seen in Figure 7(a), after roadway excavation, deformation occurred in a short time with a relatively small extent of the damage zone, in which the shear failure dominated, whereas the tensile failure appeared at the vault and bottom corner of roadway, similarly with the studies presented in [51]. In this stage, the maximum extent of yielding zone just exceeded the length of rock bolts for the top two in support, which means rock bolts could be effective to some extent. As time increased, the shear failure zone expanded to the space in soft coal mass, especially along the left and right spandrel of the roadway. Correspondingly, the roadway displacement of the roof, 


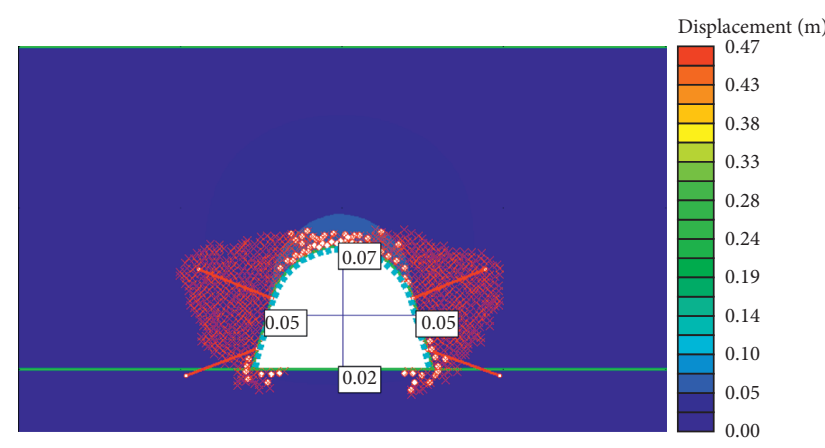

Shear

- Tension

(a)

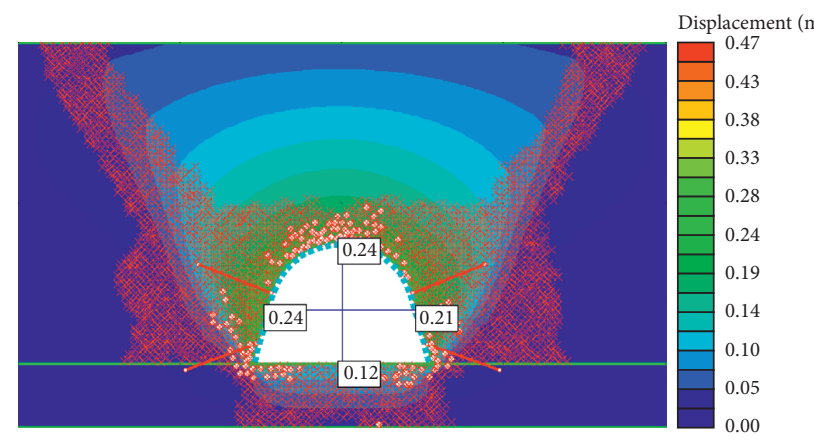

$\times$ Shear

- Tension

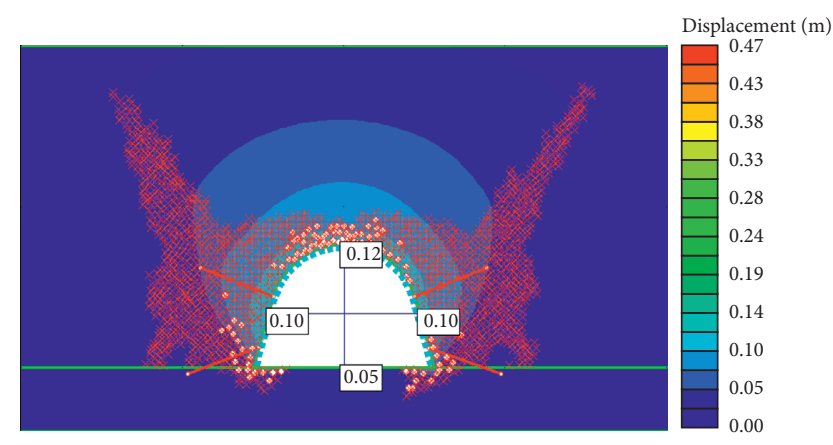

Shear

- Tension

(b)

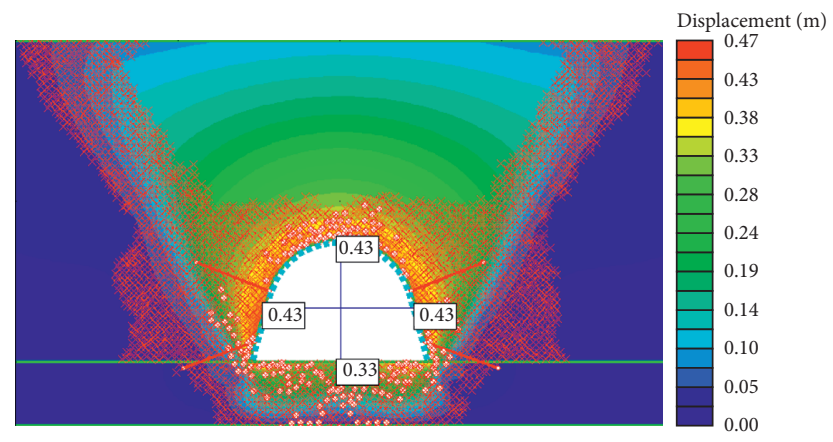

Shear

- Tension

(c)

(d)

Figure 7: Evolution of roadway deformation and the extent of damage around the roadway. (a) $3 d$. (b) $7 d$. (c) $30 d$. (d) $150 d$.

floor, and the sidewall increased significantly (Figure 7(b)). On the 30th day, the convergence of the roof and floor and the two sides reached $360 \mathrm{~mm}$ and $450 \mathrm{~mm}$, respectively, accounting for more than half of the whole deformation in monitoring, which can be found in some studies having similar on-site monitoring tendency in deep coal mines [52]. The failure band developed sharply and propagated upwards and downwards, until it reached the top mudstone stratum and bottom sandstone horizon and stopped since the strength of these two strata was higher. Two shear zones along the spandrel of roadway formed in soft coal mass, and a fully damaged area was found in the immediate floor, i.e., mudstone lithology (Figure 7(c)). After 150 days, the failure zone further enlarged and its extent exceeded the control limit of all rock bolts, indicating that the support system was unstable and ineffective. Large deformation of the roadway such as roof subsidence, floor heave, and considerable sidewall convergence was observed at this stage (Figure 7(d)). Predictably, the convergence of roadway could develop further when subjected to stresses induced by longwall panel retreat, as the surrounding rock mass totally failed in a large range. Under such harsh geoengineering conditions, geohazards are very likely to occur. The tunnel needs to be maintained frequently.

Based on the above analysis, the roadway in such conditions cannot maintain stability, and the possible reasons are as follows. (1) The surrounding coal mass with poor quality cannot bear load effectively [53]. The dramatic stress redistribution and stress concentration due to roadway excavation resulted in a large failure zone in soft coal seam around the roadway section. This causes the deterioration of the bearing capacity of coal mass. Then, the loading transferred to floor stratum (a relatively low-strength mudstone lithology) and broke the floor completely. (2) The currently used support method (i.e., rock bolts, shotcrete, and U-shaped steel set) cannot form a coordinated and stable control system in the roadway. The passive support component, U-shaped shed, cannot provide active support effect after excavation at the primary stage, and it usually bucked and failed because of uneven contact with surrounding coal mass in practice [54]. In terms of the active support component, boltshotcrete, their bearing capacity and confinement were too low to increase the residual strength of rock mass significantly, resulting in a large yielding extent. (3) The worse situation is that the failure zone extended rapidly with stress release, whereas the bearing capacity of surrounding rock mass became insufficient and the support structure became unstable, which further deteriorated the stability of roadway.

As discussed above, the coal mass properties play a vital role in the stability of the roadway. Improving the quality of soft coal mass indicates not only the reinforcement of coal but also the enhancement of integrity of support structure. Hence, the jet grouting support system is designed and compared with the conventional support schemes. 
4.3. Comparative Studies of Various Support Cases. Case studies of the jet grouting effect on roadway stability were carried out in three conditions (diameter of coalcrete column of $300 \mathrm{~mm}, 500 \mathrm{~mm}$, and $700 \mathrm{~mm}$ ), compared with the conventional support case mentioned above, i.e., without coalcrete. The detailed support materials in different cases were summarised in Table 6. The roadway section, rock mass properties, and the stresses acting on the model were identical in these numerical cases. It is noted that in practice the final status of the supported roadway is always a matter of concern to engineers. Accordingly, in this study, stresses acting on these models were the totally released stresses, i.e., the maximum stresses based on the calculation in Section 3.1. The strength parameters of coalcrete of different sizes were input to models according to the calculated results described above. In the following, the effect of various support systems on roadway stability was investigated, including deformation, failure zone, and stress distribution, and then recommendations of JG schemes were given based on the comparison results.

4.3.1. Deformation of the Roadway for Various Cases. The recorded deformation results of the roadway are comparatively shown in Figure 8. It is clearly that case 1 had a relatively even and large convergence, i.e., the similar value of roof subsidence, floor heave, and sidewall deformation. By comparison, cases 2,3 , and 4 had a relatively larger displacement at the lower wall sides than any other position of the roadway. Also, case 1 had the largest roof subsidence and sidewall convergence, followed by case 2 , case 3 , and case 4 . Moreover, case 2, case 3 , and case 4 had similar values on floor heave, while case 1 had larger value on floor heave. The similar trend for all models was that the sidewall convergence was larger than the roof-to-floor convergence. It is clear that the roof-to-floor convergence and sidewall convergence reduced with the increase of diameter of coalcrete. More concretely, compared with case 1, the roof-to-floor convergence declined by $71 \%, 72 \%$, and $75 \%$ for case 2 , case 3 , and case 4 , respectively. In terms of sidewalls convergence, it decreased by $46 \%, 55 \%$, and $63 \%$ for case 2 , case 3 , and case 4, compared with case 1.

4.3.2. Comparison of the Extent of Failure Zone. Figure 9 illustrates the failure zone distribution of roadway under four support conditions by an intuitively comparative way. Obviously, all cases had the irregular shape of failure zone and their extents were different, but all extended to three lithologies, i.e., coal mass layer, mudstone in the immediate floor, and sandstone in the main floor. Case 1 had the largest failure zone, followed by case 2 , case 3 , and case 4 , which means that with the increase of the diameter of coalcrete, the failure zone of roadway reduced significantly. In order to evaluate the extent of failure zone quantitatively, some lines such as $L_{\mathrm{w}}, L_{\mathrm{e}}, L_{\mathrm{f}}$, and $L_{\mathrm{r}}$ were defined to represent the distance of failure zone (Figure 9). As can be seen, the characteristic of " $L_{\mathrm{e}}>L_{\mathrm{w}}>L_{\mathrm{f}}>L_{\mathrm{r}}$ " indicates that the failure on roadway shoulder is larger
TABLE 6: Comparison of various support cases.

\begin{tabular}{lcccc}
\hline Cases & $\begin{array}{c}\text { Coalcrete } \\
(\mathrm{mm})\end{array}$ & $\begin{array}{c}\text { Support materials } \\
\text { Shotcrete } \\
(\mathrm{mm})\end{array}$ & $\begin{array}{c}\text { U-shaped } \\
\text { shed }\end{array}$ & $\begin{array}{c}\text { Rock } \\
\text { bolts }\end{array}$ \\
\hline${\text { Case } 1^{\mathrm{a}}}^{\mathrm{a}}$ & - & 100 & Used & Used \\
Case $^{\mathrm{b}}$ & 300 & 50 & - & - \\
Case $3^{\mathrm{b}}$ & 500 & 50 & - & - \\
Case $^{\mathrm{b}}$ & 700 & 50 & - & - \\
\hline
\end{tabular}

${ }^{\mathrm{a} C o n v e n t i o n a l ~ s u p p o r t .}{ }^{\mathrm{b}}$ Jet grouting prereinforced support.

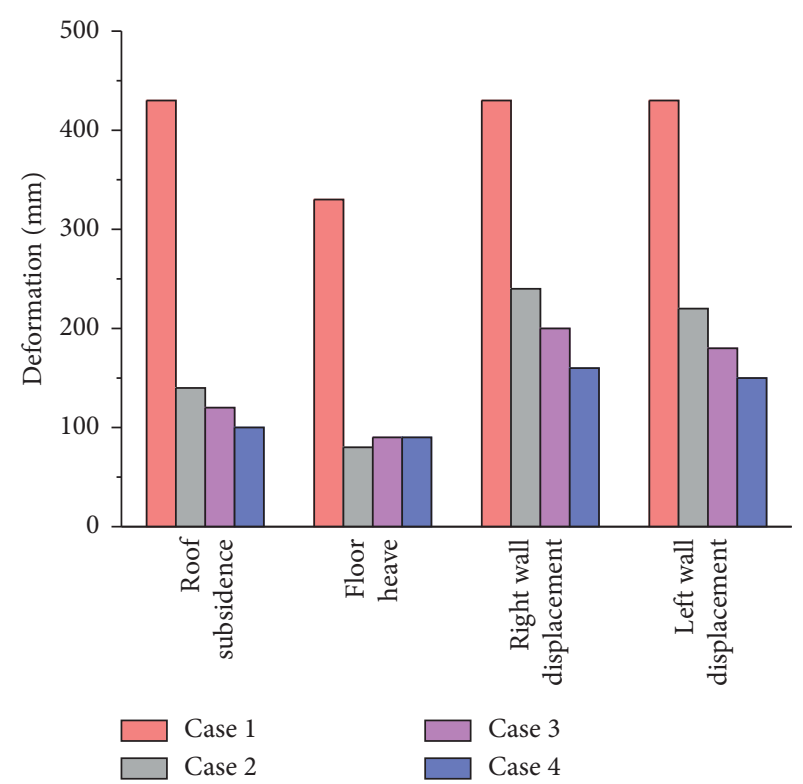

FIGURE 8: Summary of simulated results of deformation for all cases studies.

than other areas. In comparison with case 1 , the JG support cases (cases 2, 3, and 4) significantly reduced the failure zone on roadway shoulders, roof, floor, and sidewalls. More specifically, the length of the failure zone on roadway shoulder $\left(L_{\mathrm{e}}\right)$ decreased by $47 \%, 56 \%$, and $61 \%$ for cases 2, 3, and 4, respectively. The failure distance at the roof decreased by nearly $100 \%$ for jet grouting support schemes.

It is widely accepted that the elements in shear or tension failure zone can represent the development of fractures or cracks in rock materials [55]. Figure 10 depicts the failure zone distribution around roadway under various cases. More tensile cracks in case 1 occurred at the roof in coal mass, floor, and corner in mudstone (see Figure 10(a)), whereas cases 2,3 , and 4 had tension cracks mainly concentrating on bottom sidewalls of coalcrete column and the corner of roadway (Figures 10(b)-10(d)). In general, combined with the number of shear and tensile cracks, the region with more failure led to coal mass and coalcrete more dilation and therefore caused deformation and roadway convergence (see the failure distribution and the deformed profile by grey lines in Figure 10). For example, case 1 had large deformation, as it had a lot of failure cracks around the 


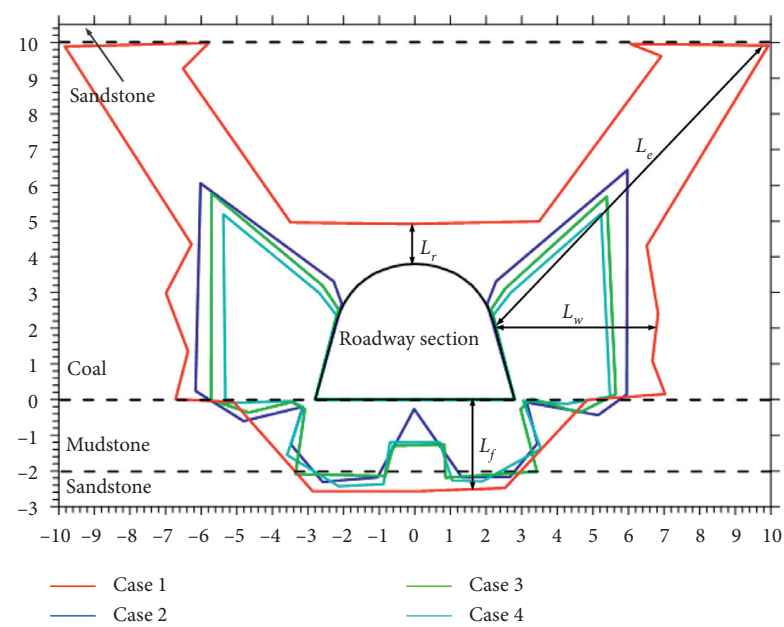

Figure 9: Comparison of failure zones for different cases.

roadway section. After the application of coalcrete columns (cases 2, 3, and 4), there was a significant reduction of shear and tension cracks on the vault and subsequently less deformation on the roof. Moreover, with the increase of the diameter of coalcrete column, the bottom and sidewall convergence declined considerably since the total number of failure cracks decreased. There was similar floor heave for cases 2, 3, and 4 because the total number of cracks was close.

After roadway excavation, though some failure cracks appeared on coalcrete because the redistributed stress exceeded the ultimate strength of coalcrete, the overall failure zone just extended into coal mass in a smaller extent. This is because though the failure occurred at the bottom sidewall of coalcrete columns (see Figures 10(b)$10(d)$ ), the relatively higher residual strength of coalcrete still had a better self-supporting capacity, which indicates that better-confined stress still acted on surrounding coal mass and thus the self-stabilization ability of surrounding coal mass could be improved notably. Consequently, a smaller damage zone would extend into coal mass than conventional support (comparing case 1 with cases 2, 3, and 4 in Figure 9).

4.3.3. Stress Distribution Analysis. It should be pointed out that the evolution of stress is closely related to the propagation of failure of the rock mass $[31,56]$. The relationship between each other can be explained as follows. For the excavation of underground constructions such as tunnels, roadway, and openings in rock mass, the failure normally first occurred in rock at shallow surface as the deviator stress reached its ultimate strength rapidly; the failing rock entered the postfailure stage but still had residual strength, causing a decline in the bearing capacity (self-supporting capacity) of shallow rock; without support, the stress further transferred and propagated into the deeper surrounding rock mass that had relatively larger confined stress meaning a higher ultimate strength of rock mass, until the concentrated stress was lower or equal to the ultimate strength of rock mass. The above processes of failure in rock mass lead to a large stress relaxation zone.
To show the effect of coalcrete on stress distribution at sidewall comparatively, observation lines were used for obtaining the maximum principal stress in the sidewall. All monitored results are shown in Figure 11. According to these, when the stress around the roadway is lower than the in situ stress (around $19 \mathrm{MPa}$ ), the areas are defined as stress release zones. Thus, there are stress release zones around the roadway, but the extent of them was different. The JG coalcrete columns can optimize the stress state to make major parts of support in better stress conditions, while some areas were still in poor force state (e.g., the stress concentration zone at the corner). When additional stress such as induced stress acted on the roof and sidewalls, stress may further transfer from the sides to the floor. The superposition effect of these stresses in roadway corners was negative for stabilizing floor and the whole JG structure, and, therefore, more attention should be paid to these areas in roadway.

It is clear that the stresses near the sidewall surface in supported cases (i.e., cases 1, 2, 3, and 4) were larger than the no-support case (approximately $0 \mathrm{MPa}$ ), which means that the bearing capacity of coal mass was increased by support systems. However, by further analysis, when the distance of monitoring points to the surface was larger than $3 \mathrm{~m}$, the stress distribution of case 1 was similar to no-support case, which signifies that the conventional support cannot significantly improve the load-bearing capacity of deep coal mass. In addition, compared with case 1 , the stress in sidewall surface in cases 2,3 , and 4 increased by $50 \%, 60 \%$, and $68 \%$, respectively, indicating that the bearing capacity of coalcrete was much larger than coal and it also increased with the diameter of coalcrete. Though the coalcrete columns have failed (shown in Figures 10(b)-10(d)), the stress in coalcrete (see the region marked by a blue dotted circle in Figure 11) still increased greatly with the distance from the roadway surface, which means the failed coalcrete still bore the load effectively. Interestingly, a stress dissipation phenomenon in cases 2, 3, and 4 appeared beyond the coalcrete column, and all values of dropped stress in coal mass were larger than the stress at the same position in case 1 or nosupport case. That means the residual strength of coal mass was enhanced after coalcrete application.

4.4. Selection Principles and Suggestions to the JG Support System. Based on the results and analysis above, it is clear that the jet grouting support system ("coalcrete + shotcrete") is promising for stabilizing roadway. In comparison with the conventional support system, i.e., "bolt + shotcrete + Ushaped steel set," JG support system has many benefits on roadway stability such as less roadway deformation, the smaller extent of failure zone, and optimal stress states. Moreover, with the increase of the diameter of jet-grouted coalcrete column, the control effect gets better. However, the diameter of approximately $400 \mathrm{~mm}$ to $600 \mathrm{~mm}$ is more economic and practicable in the field, as bigger coalcrete column needs higher jet pressure and more cement grout, which is money consuming and uneconomic [57, 58]. The selection of the coalcrete diameter depends on the 

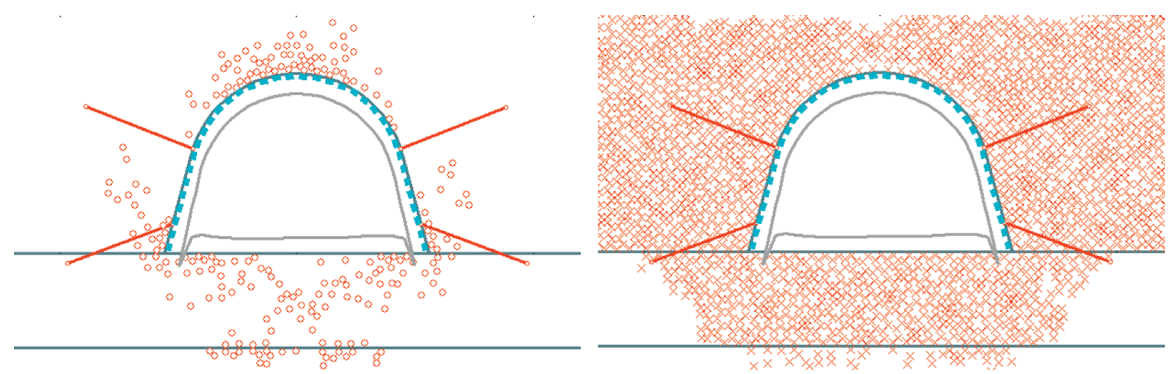

$\times$ Shear

O Tension

(a)
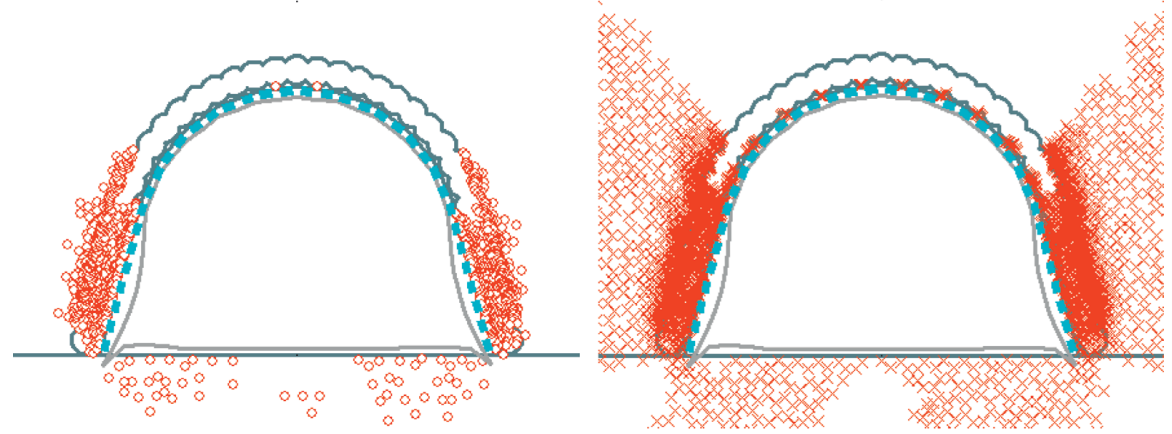

$\times$ Shear

○ Tension

(b)
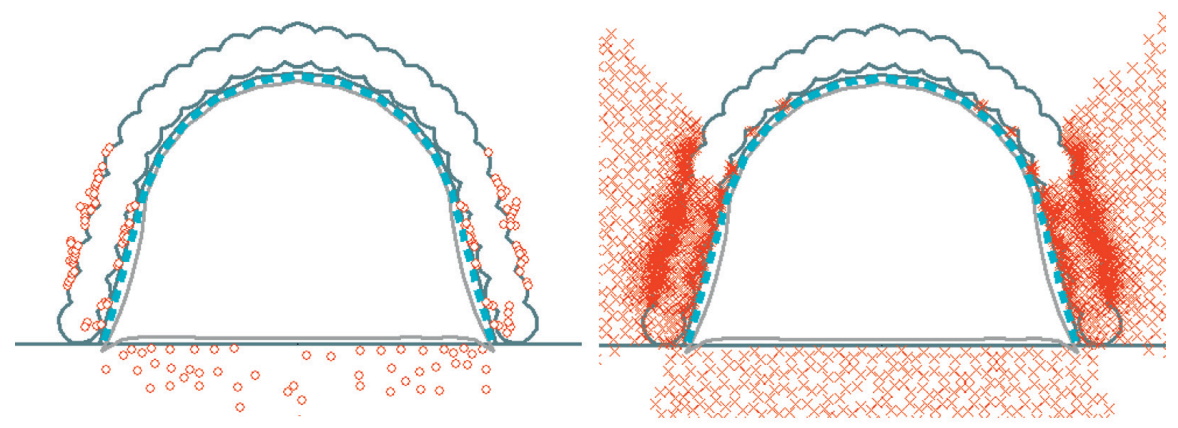

$\times$ Shear

○ Tension

(c)
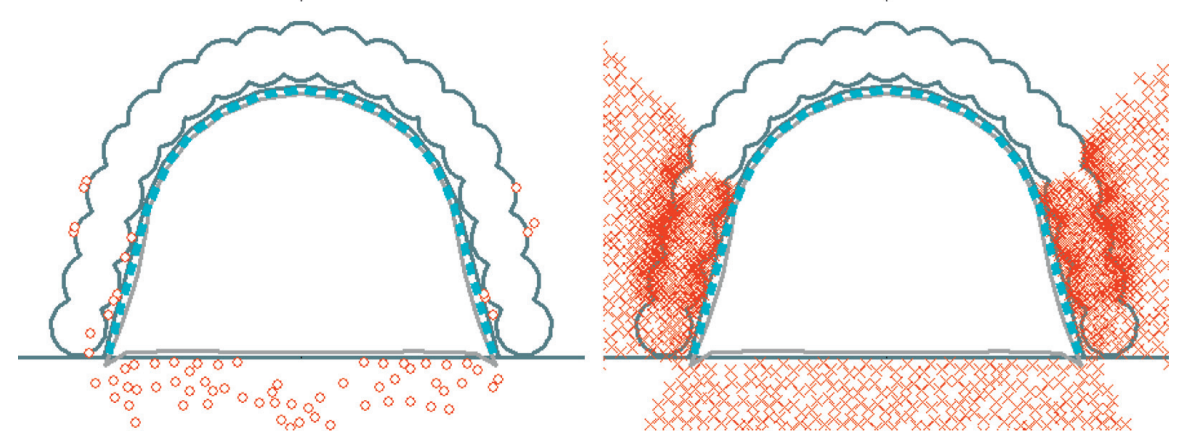

$\times$ Shear

O Tension

(d)

FIgURE 10: Failure patterns for different support cases. (a) Case 1, (b) case 2, (c) case 3, and (d) case 4. 


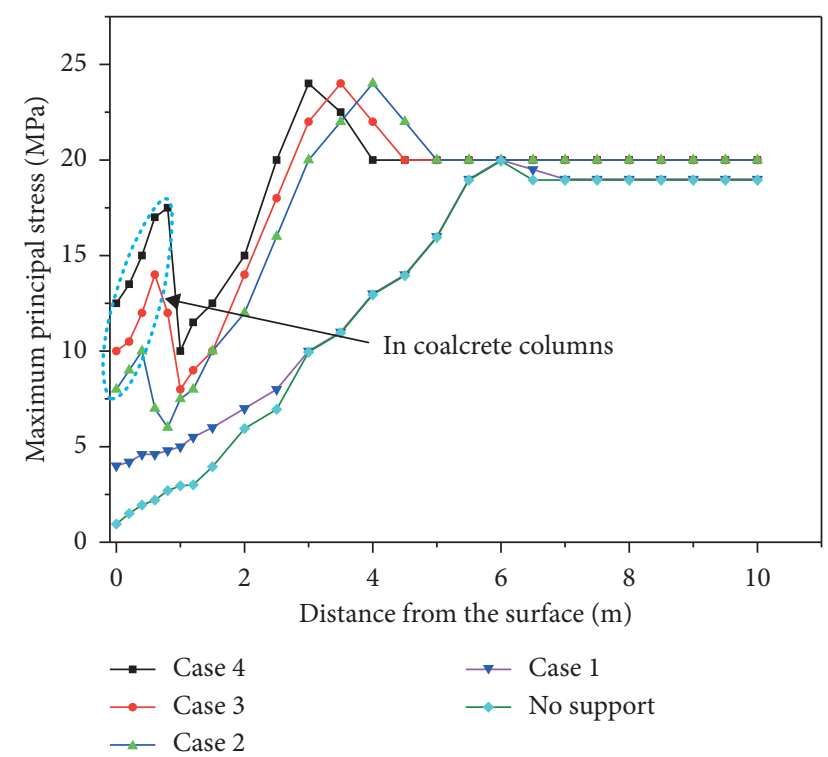

Figure 11: Maximum stress along the observation lines in sidewall under different cases.

requirements of control effect and geological conditions of roadway in practice. Also, it should be pointed out that there are still some defects of JG support system, e.g., some failure at bottom sidewalls and stress concentration at the corner of roadway. Subsequently, to keep the stability of JG roadway in the long term, some suggestions are additionally proposed based on previous successful experience in coal mines [59]:

(1) The rock bolts or cables are recommended to install along roadway shoulder and sidewalls. By the jet grouting support method, though failure zone of the rock mass is in a controllable extent, some commonly used support components such as cable bolts and rock bolts would be used for further reinforcement. The bolts can effectively bond the yielding coal to intact coal mass to avoid the sudden collapse of the roadway surface.

(2) The inverted arch is suggested for optimizing the stress conditions in the floor and bottom corner of the roadway. Due to the angle effect of the JG support system on the roadway, the high-stress concentration zone is in the corner, which is negative for the long-term stability of the whole support structure. The inverted arch can not only improve the stress state but also provide a certain bearing capacity, which could effectively transfer the stress into deep rock and reduce floor heave.

\section{Concluding Remarks}

This paper presented a relatively new prereinforcement support system of the roadway with soft coal mass, i.e., jet grouting (JG) method. Based on the field observation of JG in coal mass, this method met the requirements in techniques and could be used for stabilizing roadway in deep mines. According to the data collected from the field and laboratory, the GSI was used for estimating coal measure rock mass properties. A numerical model was further established and then verified, which confirms the reliability of input parameters.

The mechanical properties of coalcrete produced from JG in coal mass were obtained by a series of tests and their size effect was considered. Furthermore, according to the verified model and the determined mechanical parameters of coalcrete, three JG numerical models were established and compared with the conventional support case (the currently used support approach, "rock bolts + U-shaped steel set + shotcrete"). The results show that the JG method could promote roadway stability by reducing the deformation, failure zone and optimizing the stress conditions.

In addition, the mechanism of this new support on stabilizing roadway was revealed. The generated coalcrete columns have higher strength, and larger deformationresisting ability can form a stable arch structure. Some advice such as installing rock/cable bolts and inverted arch on floor were further proposed for the stability of roadway by JG treatment. This study mainly focuses on the comparison of conventional support and JG support on roadway stability by numerical modeling methods, and in the future, the more detailed application information of this innovative technique for roadway would be studied and analyzed.

\section{Data Availability}

The Microsoft Excel Worksheet data used to support the findings of this study are available from the corresponding author (yuantiansun@cumt.edu.cn) upon request.

\section{Conflicts of Interest}

The authors declare that they have no conflicts of interest regarding the publication of this paper.

\section{Authors' Contributions}

Guichen Li and Yuantian Sun carried out original draft preparation. Junfei Zhang performed reviewing and editing. Guichen $\mathrm{Li}$ was responsible for supervision. Guichen $\mathrm{Li}$ carried out funding acquisition. Qianjin Zhang was involved in conceptualization. Investigation was performed by Changlun Sun, methodology by Suhui Zhang, and simulation by Ruiyang Bi.

\section{Acknowledgments}

This work was supported by the projects of the National Key Research and Development Program (2016YFC0600901) and National Natural Science Foundation of China (Grant nos. 51574224 and 51704277). The authors are grateful to Huaibei Mining (Group) Co., Ltd. Special thanks are due to Dr. Zuqi Wang for her encouragement and help.

\section{References}

[1] E. T. Brown, "The evolution of support and reinforcement philosophy and practice for underground mining 
excavations," in Rock Support and Reinforcement Practice in Mining, pp. 3-17, Taylor \& Francis, Abingdon, UK, 2018.

[2] J. A. Smith, H. L. Ramandi, C. Zhang, and W. Timms, "Analysis of the influence of groundwater and the stress regime on bolt behaviour in underground coal mines," International Journal of Coal Science \& Technology, vol. 6, no. 2, pp. 286-300, 2019.

[3] J. Zuo, J. Wang, and Y. Jiang, "Macro/meso failure behavior of surrounding rock in deep roadway and its control technology," International Journal of Coal Science \& Technology, vol. 6, no. 3, pp. 301-319, 2019.

[4] Y. Zhao, N. Liu, X. Zheng, and N. Zhang, "Mechanical model for controlling floor heave in deep roadways with U-shaped steel closed support," International Journal of Mining Science and Technology, vol. 25, no. 5, pp. 713-720, 2015.

[5] H. Wagner, "Deep mining: a rock engineering challenge," Rock Mechanics and Rock Engineering, vol. 52, no. 5, pp. 1417-1446, 2019.

[6] Y. Sun, G. Li, J. Zhang, and J. Xu, "Failure mechanisms of rheological coal roadway," Sustainability, vol. 12, no. 7, p. 2885, 2020.

[7] Q. S. Liu, Y. S. Kang, and Y. Q. Bai, "Research on supporting method for deep rock roadway with broken and soft surrounding rock in Guqiao Coal Mine," Rock and Soil Mechanics, vol. 32, no. 10, pp. 3097-3104, 2011.

[8] S. C. Li, Q. Wang, H. T. Wang et al., "Model test study on surrounding rock deformation and failure mechanisms of deep roadways with thick top coal," Tunnelling and Underground Space Technology, vol. 47, pp. 52-63, 2015.

[9] Z. Guo, Q. Wang, S. Yin et al., "The creep compaction behavior of crushed mudstones under the step loading in underground mining," International Journal of Coal Science \& Technology, vol. 6, no. 3, pp. 408-418, 2019.

[10] M. H. Salimian, A. Baghbanan, H. Hashemolhosseini, M. Dehghanipoodeh, and S. Norouzi, "Effect of grouting on shear behavior of rock joint," International Journal of Rock Mechanics and Mining, vol. 98, pp. 159-166, 2017.

[11] Y. Sun, G. Li, H. Basarir, A. Karrech, and M. R. Azadi, "Laboratory evaluation of shear strength properties for cement-based grouted coal mass," Arabian Journal of Geosciences, vol. 12, no. 22, 2019.

[12] W. Yu, W. Wang, X. Chen, and S. Du, "Field investigations of high stress soft surrounding rocks and deformation control," Journal of Rock Mechanics and Geotechnical Engineering, vol. 7, no. 4, pp. 421-433, 2015.

[13] M. He, G. Li, J. Wang, and J. Cai, "Study on supporting design for large area serious roof caving of deep soft rock roadway in Xing'an coal mine," Yanshilixue Yu Gongcheng Xuebao/ Chinese Journal of Rock Mechanics and Engineering, vol. 26, no. 5, pp. 959-964, 2007.

[14] Y. Kang, Q. Liu, H. Xi, and G. Gong, "Improved compound support system for coal mine tunnels in densely faulted zones: a case study of China's Huainan coal field," Engineering Geology, vol. 240, pp. 10-20, 2018.

[15] S. Li, W. W. Han, Q. Zhang, R. Liu, and X. Weng, "Research on time-dependent behavior of viscosity of fast curing grouts in underground construction grouting," Chinese Journal of Rock Mechanics and Engineering, vol. 32, no. 1, pp. 1-7, 2013.

[16] Y. Sun, G. Li, J. Zhang, and D. Qian, "Prediction of the strength of rubberized concrete by an evolved random forest model," Advances in Civil Engineering, vol. 2019, Article ID 5198583, 7 pages, 2019.

[17] T. Yahiro and H. Yoshida, "Induction grouting method utilizing high speed water jet," in Proceedings of the Eighth
International Conference on Soil Mechanics and Foundation Engineering, vol. 4, pp. 359-362, Moscow, Russia, August 1973.

[18] M. Ochmański, G. Modoni, and J. Bzówka, "Numerical analysis of tunnelling with jet-grouted canopy," Soils and Foundations, vol. 55, no. 5, pp. 929-942, 2015.

[19] A. Da Vià, M. Marotta, and G. Peach, "High pressure jet grouting in tunnels-a case study," in Proceedings of the International World Tunnel Congress and the 31st ITA General Assembly, pp. 477-483, Istanbul, Turkey, May 2005.

[20] M. Heidari and F. Tonon, "Ground reaction curve for tunnels with jet grouting umbrellas considering jet grouting hardening," International Journal of Rock Mechanics and Mining Sciences, vol. 76, pp. 200-208, 2015.

[21] J. Tinoco, A. G. Correia, and P. Cortez, "A novel approach to predicting Young's modulus of jet grouting laboratory formulations over time using data mining techniques," Engineering Geology, vol. 169, pp. 50-60, 2014.

[22] J. Tinoco, A. Gomes Correia, and P. Cortez, "Application of data mining techniques in the estimation of the uniaxial compressive strength of jet grouting columns over time," Construction and Building Materials, vol. 25, no. 3, pp. 1257-1262, 2011.

[23] P. G. Asteris, P. C. Roussis, and M. G. Douvika, "Feed-forward neural network prediction of the mechanical properties of sandcrete materials," Sensors, vol. 17, no. 6, 2017.

[24] P. G. Asteris, K. G. Kolovos, A. Athanasopoulou, V. Plevris, and G. Konstantakatos, "Investigation of the mechanical behaviour of metakaolin-based sandcrete mixtures," European Journal of Environmental and Civil Engineering, vol. 23, no. 3, pp. 300-324, 2019.

[25] Y. Sun, J. Zhang, G. Li, Y. Wang, J. Sun, and C. Jiang, "Optimized neural network using beetle antennae search for predicting the unconfined compressive strength of jet grouting coalcretes," International Journal for Numerical and Analytical Methods in Geomechanics, vol. 43, no. 4, pp. 801813, 2019.

[26] Y. Sun, G. Li, and J. Zhang, "Developing hybrid machine learning models for estimating the unconfined compressive strength of jet grouting composite: a comparative study," Applied Sciences, vol. 10, no. 5, p. 1612, 2020.

[27] Y. Sun, J. Zhang, G. Li et al., "Determination of Young's modulus of jet grouted coalcretes using an intelligent model," Engineering Geolog, vol. 252, pp. 43-53, 2019.

[28] Y. Sun, G. Li, J. Zhang, and D. Qian, "Experimental and numerical investigation on a novel support system for controlling roadway deformation in underground coal mines," Energy Science \& Engineering, vol. 8, no. 2, pp. 490-500, 2019.

[29] E. Hoek, T. G. Carter, and M. S. Diederichs, "Quantification of the geological strength index chart," in Proceedings of the 47th US Rock Mechanics/Geomechanics Symposium, American Rock Mechanics Association, San Francisco, CA, USA, June 2013.

[30] Z. T. Bieniawski, Engineering Rock Mass Classifications: A Complete Manual for Engineers and Geologists in Mining, Civil, and Petroleum Engineering, John Wiley \& Sons, Hoboken, NJ, USA, 1989.

[31] E. Hoek and E. T. Brown, "Practical estimates of rock mass strength," International Journal of Rock Mechanics and Mining Sciences, vol. 34, no. 8, pp. 1165-1186, 1997.

[32] E. Hoek, P. G. Marinos, and V. P. Marinos, "Characterisation and engineering properties of tectonically undisturbed but lithologically varied sedimentary rock masses," International 
Journal of Rock Mechanics and Mining Sciences, vol. 42, no. 2, pp. 277-285, 2005.

[33] E. Hoek and M. S. Diederichs, "Empirical estimation of rock mass modulus," International Journal of Rock Mechanics and Mining Sciences, vol. 43, no. 2, pp. 203-215, 2006.

[34] M. Karakus, "Appraising the methods accounting for 3D tunnelling effects in 2D plane strain FE analysis," Tunnelling and Underground Space Technology, vol. 22, no. 1, pp. 47-56, 2007.

[35] D. M. Potts, L. Zdravkovic, and L. Zdravković, Finite Element Analysis in Geotechnical Engineering: Application, Vol. 2, Thomas Telford, London, UK, 2001.

[36] M. Barla and J. Bzowka, "Comparing numerical alternatives to model jet grouting in tunnels," Electronic Journal of Geotechnical Engineering, vol. 18, pp. 2997-3008, 2013.

[37] H. Basarir, Y. Sun, and G. Li, "Gateway stability analysis by global-local modeling approach," International Journal of Rock Mechanics and Mining Sciences, vol. 113, pp. 31-40, 2019.

[38] W. Li, J. Bai, S. Peng, X. Wang, and Y. Xu, "Numerical modeling for yield pillar design: a case study," Rock Mechanics and Rock Engineering, vol. 48, no. 1, pp. 305-318, 2014.

[39] W.-L. Shen, J.-B. Bai, W.-F. Li, and X.-Y. Wang, "Prediction of relative displacement for entry roof with weak plane under the effect of mining abutment stress," Tunnelling and Underground Space Technology, vol. 71, pp. 309-317, 2018.

[40] C. Zhao, A. Alimardani Lavasan, T. Barciaga, C. Kämper, P. Mark, and T. Schanz, "Prediction of tunnel lining forces and deformations using analytical and numerical solutions," Tunnelling and Underground Space Technology, vol. 64, pp. 164-176, 2017.

[41] K. Il Song, G. C. Cho, S. B. Chang, and I. M. Lee, "Beam-spring structural analysis for the design of a tunnel pre-reinforcement support system," International Journal of Rock Mechanics and Mining Sciences, vol. 59, pp. 139-150, 2013.

[42] M. Panet and A. Guenot, "Analysis of convergence behind the face of a tunnel: tunnelling 82 , proceedings of the $3 \mathrm{rd}$ international symposium, Brighton, 7-11 June 1982, P197-204. Publ London: IMM, 1982," International Journal of Rock Mechanics and Mining Sciences \& Geomechanics Abstracts, vol. 20, no. 1, p. A16, 1983.

[43] E. Hoek and P. Marinos, "Predicting tunnel squeezing problems in weak heterogeneous rock masses," Tunnels and Tunnelling International, vol. 32, no. 11, pp. 45-51, 2000.

[44] G. U. O. Rui, F. Yong, and H. E. Chuan, "Study on the correlation between stress release and displacement release during tunnel excavation," Journal of Railway Engineering Society, vol. 27, no. 9, pp. 46-50, 2010.

[45] Y. Sun, G. Li, J. Zhang, and D. Qian, "Experimental and numerical investigation on a novel support system for controlling roadway deformation in underground coal mines," Energy Science \& Engineering, vol. 8, no. 2, pp. 490-500, 2020.

[46] S. Q. Yang, M. Chen, H. W. Jing, K. F. Chen, and B. Meng, "A case study on large deformation failure mechanism of deep soft rock roadway in Xin'an coal mine, China," Engineering Geology, vol. 217, pp. 89-101, 2017.

[47] C. Jian-long, Y. Sheng-qi, L. I. Xue-hua, P. Yu-cong, Z. Weisheng, and T. Wen-ling, "Impact of longitudinal displacement profile relaxation on contract force acted on double shield TBM in squeezing ground," Rock and Soil Mechanics, vol. 37, no. 5, pp. 1399-U424, 2016.

[48] Z. P. Bažant, "Size effect in blunt fracture: concrete, rock, metal," Journal of Engineering Mechanics, vol. 110, no. 4, pp. 518-535, 1984.
[49] O. Helson, A. L. Beaucour, J. Eslami, A. Noumowe, and P. Gotteland, "Physical and mechanical properties of soilcrete mixtures: soil clay content and formulation parameters," Construction and Building Materials, vol. 131, pp. 775-783, 2017.

[50] P. J. N. PELLS, "Uniaxial strength testing," in Rock Testing and Site Characterization, pp. 67-85, Elsevier, Amsterdam, Netherlands, 1993.

[51] P. H. S. W. Kulatilake, Q. Wu, Z. Yu, and F. Jiang, "Investigation of stability of a tunnel in a deep coal mine in China," International Journal of Mining Science and Technology, vol. 23, no. 4, pp. 579-589, 2013.

[52] G. Zhang, F. He, H. Jia, Y. Lai, "Analysis of gateroad stability in relation to yield pillar size: a case study," Rock Mechanics and Rock Engineering, vol. 50, no. 5, pp. 1263-1278, 2017.

[53] B. Shen, "Coal mine roadway stability in soft rock: a case study," Rock Mechanics and Rock Engineering, vol. 47, no. 6, pp. 2225-2238, 2014.

[54] Q. Wang, B. Jiang, R. Pan et al., "Failure mechanism of surrounding rock with high stress and confined concrete support system," International Journal of Rock Mechanics and Mining Sciences, vol. 102, pp. 89-100, 2018.

[55] Q. S. Bai, S. H. Tu, F. T. Wang, X. G. Zhang, H. S. Tu, and Y. Yuan, "Observation and numerical analysis of the scope of fractured zones around gateroads under longwall influence," Rock Mechanics and Rock Engineering, vol. 47, no. 5, pp. 1939-1950, 2014.

[56] M. Cai, "Influence of stress path on tunnel excavation response-numerical tool selection and modeling strategy," Tunnelling and Underground Space Technology, vol. 23, no. 6, pp. 618-628, 2008.

[57] Y. Sun, G. Li, J. Zhang, and D. Qian, "Stability control for the rheological roadway by a novel high-efficiency jet grouting technique in deep underground coal mines," Sustainability, vol. 11, no. 22, p. 6494, 2019.

[58] Y. Sun, G. Li, and J. Zhang, "Investigation on jet grouting support strategy for controlling time-dependent deformation in the roadway," Energy Science \& Engineering, vol. 8, no. 4, pp. 1-8, 2020.

[59] J. Coggan, F. Gao, D. Stead, and D. Elmo, "Numerical modelling of the effects of weak immediate roof lithology on coal mine roadway stability," International Journal of Coal Geology, vol. 90-91, pp. 100-109, 2012. 